\section{Shrinkage of Selected Two-component Container Media}

\author{
Mark A. Nash ${ }^{1}$ and Franklin A. Pokorny ${ }^{2}$ \\ Department of Horticulture, University of Georgia, Athens, GA 30602
}

Additional index words. physical property, particle-size distribution, pine bark, peat, sand, perlite

\begin{abstract}
Component and particle-size effects on shrinkage of two-component potting media were determined. Milled pine bark-sand mixtures were used to determine particle-size effects on shrinkage. Shrinkage curves formed an inverted $\mathrm{V}$ with maximum shrinkage at the 1:1 (v/v) ratio. No shrinkage occurred when bark was mixed with bark or sand with sand. Shrinkage increased linearly in the range of $0 \%$ to $50 \%$ bark and decreased linearly in the range of $50 \%$ to $100 \%$ bark. Each half of the shrinkage curve was a mirror image of the other half. Shrinkage curves for peat-sand and peatperlite were similar in form to that of bark-sand media.
\end{abstract}

Shrinkage, a commonly used nursery trade term, refers to loss of bulk volume in container media. This change may occur either during medium preparation or after the medium is placed in containers. When medium components differing in particle size are mixed, mixture volume will be less than the additive volume of individual components (Spomer, 1974, 1975, 1979). This phenomenon is attributed to settling of fine particles into large pores located between coarse particles. Medium shrinkage also occurs during plant production because of microbial decomposition of the organic component(s). Physical and chemical factors further reduce medium volume (Whitcomb, 1984). Shrinkage during plant production results in increased water retention (not to be confused with available water) and decreased aeration within the medium (Whitcomb, 1984).

Shrinkage needs to be accounted for, as it affects costs, component inventory, and other factors. If no shrinkage is assumed, calculational errors may occur when fertilizer, soilapplied pesticides, and growth regulator rates are determined. These errors may result in over-application of fertilizers, increased groundwater contamination (Mills and Alexander, 1976; Hedlin, 1971; Perry, 1987; Yanaba et al., 1973), and excessive application of pesticides and other chemicals. Thus, a grower may not only face economic losses but could be in violation of a legal document, the pesticide label (Perry, 1987).

Pokorny et al. (1986) reported that the shrinkage curve for synthesized pine barksand potting mixtures approximates an inverted $\mathrm{V}$, with maximum shrinkage obtained at the $1: 1(\mathrm{v} / \mathrm{v})$ ratio, the left side of the shrinkage curve being a mirror image of the

Received for publication 9 Feb. 1989. Supported by state and Hatch funds allocated to the Georgia Agr. Expt. Sta. The cost of publishing this paper was defrayed in part by the payment of page charges. Under postal regulations, this paper therefore must be hereby marked advertisement solely to indicate this fact.

${ }^{1}$ Graduate Student.

${ }^{2}$ Professor. right side. However, the shrinkage form is unknown for nonsynthesized bark-sand media and media composed of components other than bark and sand. Objectives of this research were to: 1) determine particle-size effects of pine bark-sand potting mixtures on shrinkage, and 2) determine the form of shrinkage curves for two-component potting mixtures composed of peat-sand and peatperlite.

Pine bark-sand (Expt. 1). Particle-size effects on shrinkage were evaluated using pinebark-sand mixes. Three grades of bark and of sand, based on particle diameter, were used:1) bark-coarse (>4.76 mm), medium $(0.85$ to $1.0 \mathrm{~mm})$, and ungraded (polydispersed particles); 2) sand-medium (0.85 to $1.0 \mathrm{~mm})$, fine $(<0.425 \mathrm{~mm})$, and ungraded (polydispersed particles). Each of the following media was prepared: a) coarse bark$0.42+0.15 S$, df $28, r=0.94$ fine sand, b) medium bark-medium sand, and c) ungraded bark-ungraded sand in the following volume ratios: a) 1 bark : 0 sand, b) 3 bark : 1 sand, c) 1 bark : 1 sand, d) 1 bark : 3 sand, and e) 0 bark : 1 sand.

Shrinkage was determined for each medium and mixing ratio from which shrinkage curves were developed. Medium samples with an additive volume (bark + sand) of $90 \mathrm{ml}$ were prepared by determining bulk density for each component at maximum settling using a modified wrist-action shaker (Pokorny and Henny, 1984) and calculating the weight of each component needed to achieve desired ratios. Shrinkage was determined as percent difference between additive volume of samples and volume at maximum settling. Samples were arranged in a randomized block design with 10 replicates. Regression equations were developed for each half of the shrinkage curve $(0 \%$ to $50 \%$ bark and $50 \%$ to $100 \%$ bark) to compare equality of the two halves. Regression coefficients for the two equations were statistically compared (Gomez and Gomez, 1984).

Maximum shrinkage occurred at the 1:1 $(\mathrm{v} / \mathrm{v})$ ratio in coarse bark-fine sand and ungraded bark-ungraded sand media (Fig. 1). No shrinkage occurred with $100 \%$ bark or $100 \%$ sand or with medium bark-medium sand substrates regardless of the volumetric ratio of components (Fig. 1). Shrinkage was greater in coarse bark-fine sand than in ungraded bark-ungraded sand in all mixtures, except when bark was mixed with bark and sand with sand (Fig. 1). Furthermore, the magnitude of change in shrinkage per unit increment of bark was influenced by the magnitude of differences in particle size between components (Fig. 1). Shrinkage increased linearly with additional increments

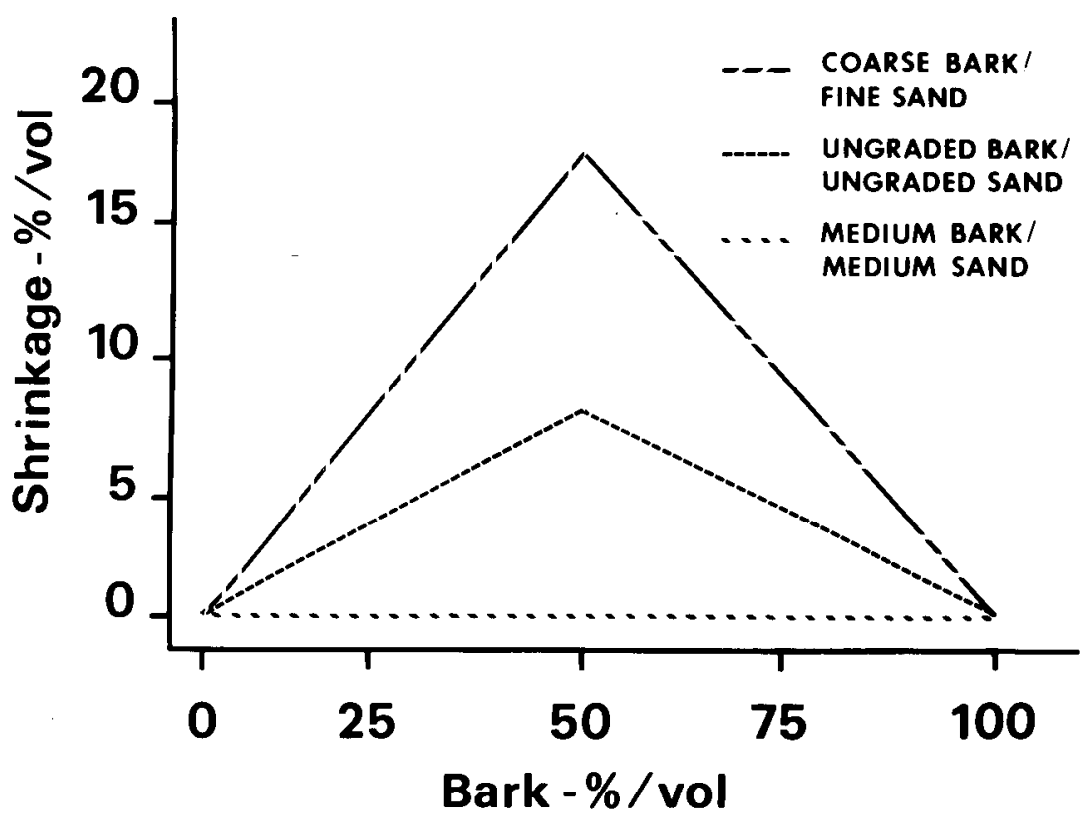

Fig. 1. Shrinkage curves for potting media prepared from three grades each of pine bark and sand. Coarse bark-fine sand: $0 \%$ to $50 \%$ bark: $\hat{Y}=0.53+0.34 \mathrm{~B}$, df $28, r=0.98 ; 50 \%$ to $100 \%$ bark: $\hat{\mathrm{Y}}=0.73+0.33 \mathrm{~S}$, df $28, r=0.96$. Medium bark-medium sand: $0 \%$ to $50 \%$ bark: $\hat{\mathrm{Y}}=0.36+$ $0.00 \mathrm{~B}$, df $28, r=0$; $50 \%$ to $100 \%$ bark: $\hat{\mathrm{Y}}=0.36+0.00 \mathrm{~S}$, df $28, r=0$. Ungraded barkungraded sand: $0 \%$ to $50 \%$ bark: $\hat{\mathrm{Y}}=0.80+0.14 \mathrm{~B}, \mathrm{df} 28, r=0.93 ; 50 \%$ to $100 \%$ bark: $\hat{\mathrm{Y}}=$ 


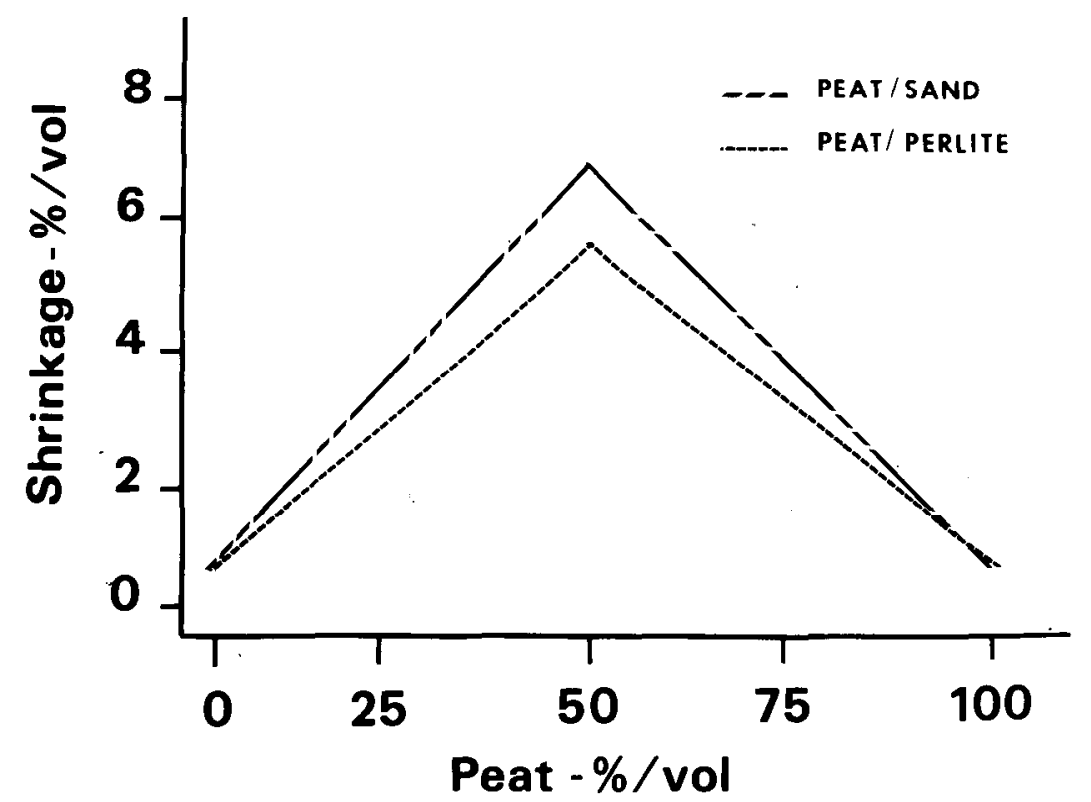

Fig. 2. Shrinkage curves for peat-sand and peat-perlite potting media. Peat-sand: $0 \%$ to $50 \%$ peat: $\hat{\mathrm{Y}}=0.72+0.12 \mathrm{P}$, df $28, r=0.88 ; 50 \%$ to $100 \%$ peat; $\hat{\mathrm{Y}}=0.64+0.12 \mathrm{~S}$, df $28, r=0.88$. Peat-perlite: $0 \%$ to $50 \%$ peat: $\hat{\mathrm{Y}}=0.64+0.10 \mathrm{P} ; \mathrm{df} 28, r=0.85 ; 50 \%$ to $100 \%$ peat: $\hat{\mathrm{Y}}=0.85$ +0.09 perlite, df $28, r=0.85$.

of bark in the $0 \%$ to $50 \%$ bark range and decreased linearly with increasing increments of bark thereafter (Fig. 1). Each half of the shrinkage curve for coarser bark-fine sand and ungraded bark-ungraded sand can be described by a linear equation. Both halves of the curve for coarse bark-fine sand and ungraded bark-ungraded sand are mirror images of each other. Value of the slopes was not statistically different, but was opposite in sign.

Peat-sand, peat-perlite (Expt. 2). Shrinkage-curves for milled Canadian sphagnum peat-sand and peat-perlite mixtures were developed. All samples were prepared as in Expt. 1 without regard to particle-size distribution.

Shrinkage curves for peat-sand and peatperlite media were similar in form to those of pine bark-sand (Fig. 2). Each half of the shrinkage curve was linear and a mirror image of the other.
In the broadest meaning, shrinkage, as it pertains to container media, can be defined as reduction in volume because of disparity in particle-size distribution, and physical and components when placed in a container. Data and results presented here concern only that aspect of shrinkage involving particle-size disparity between two components.

Maximum shrinkage occurred when particle-size disparity was at a maximum between two components (Fig. 1). Conversely, minimum shrinkage occurred when particlesize disparity was at a minimum between two components. When two components had essentially the same particle-size distribution, shrinkage was negligible (Fig. 1).

Shrinkage curves for bark-sand container when particle size of the two components is similar. In the latter case, no shrinkage occurs and the line is horizontal. Shrinkage biological forces acting on the mixture of media form an inverted V (Fig. 1), except curves for peat-sand and peat-perlite media have essentially the same form as those of bark-sand mixes (Fig. 2). Each arm of the shrinkage curve is linear, in contrast to that reported by Pokorny et al. (1986). However, right and left sides are mirror images of each other. Thus, only shrinkage at the 1:1 (v/v) ratio of two components needs to be determined. Then a straight line is plotted to $0 \%$ shrinkage at $100 \%$ bark and $100 \%$ sand to ascertain the curve. Shrinkage for all other ratios of the two components can be estimated from the plotted curve.

\section{Literature Cited}

Gomez, K.A. and A.A. Gomez. 1984. Statistical procedures for agricultural research. Wiley, New York.

Hedlin, R.A. 1971. Nitrate contamination of groundwater in the Neepawa-Langruth area of Manitoba. Can. J. Soil Sci. 51:75-84.

Mills, A. and M. Alexander. 1976. Factors affecting dimethylnitrosamine formation in samples of soil and water. J. Env. Quality 5:437440.

Perry, E. 1987. The label, the law and you. Amer. Nurseryman 166:98-100.

Pokorny, F.A., P.G. Gibson, and M.G. Dunavent. 1986. Prediction of bulk density of a pine bark and/or sand potting media from laboratory analysis of individual components. J. Amer. Soc. Hort. Sci. 111:8-11.

Pokorny, F.A. and B.K. Henny. 1984. Construction of a milled pine bark and sand medium from component particles. I. Bulk density: a tool for predicting component volumes. J. Amer. Soc. Hort. Sci. 109:770-773.

Spomer, L.A. 1974. Optimizing container soil amendment: The "threshold proportion" and prediction of porosity. HortScience 9:532-533.

Spomer, L.A. 1975. How much hardwood bark is necessary for proper container-soil amendment? For. Prod. J. 25:57-59.

Spomer, L.A. 1979. Three simple demonstrations of the physical effects of soil amendment. HortScience 14:75-77.

Whitcomb, C.E. 1984. Plant production in containers. Lacebark, Stillwater, Okla.

Yanaba, A.A., W. Verstraete, and M. Alexander. 1973. Formation of dimethylnitrosamine, a carcinogen and mutagen, in soils treated with nitrogen compounds. Soil Sci. Soc. Amer. Proc. $37: 565-568$ 